\title{
Fish, fishing and pollutant reduction in the Baltic Sea
}

\section{Supplementary Information}

${ }^{1}$ Department of Marine Ecology and Aquaculture

Danish Institute for Fisheries Research

Kavalergården 6

DK-2920 Charlottenlund

Denmark

Tel.: $+45-3396-3403$

Fax: $+45-3396-3434$

Email: brm@dfu.min.dk

${ }^{2}$ Department of Systems Ecology

Stockholm University

SE-106 91 Stockholm

Sweden 
Contents:

1. Figures $\mathrm{S} 1$ and $\mathrm{S} 2$

2. Estimation of PCB removal associated with cod muscle

3. References

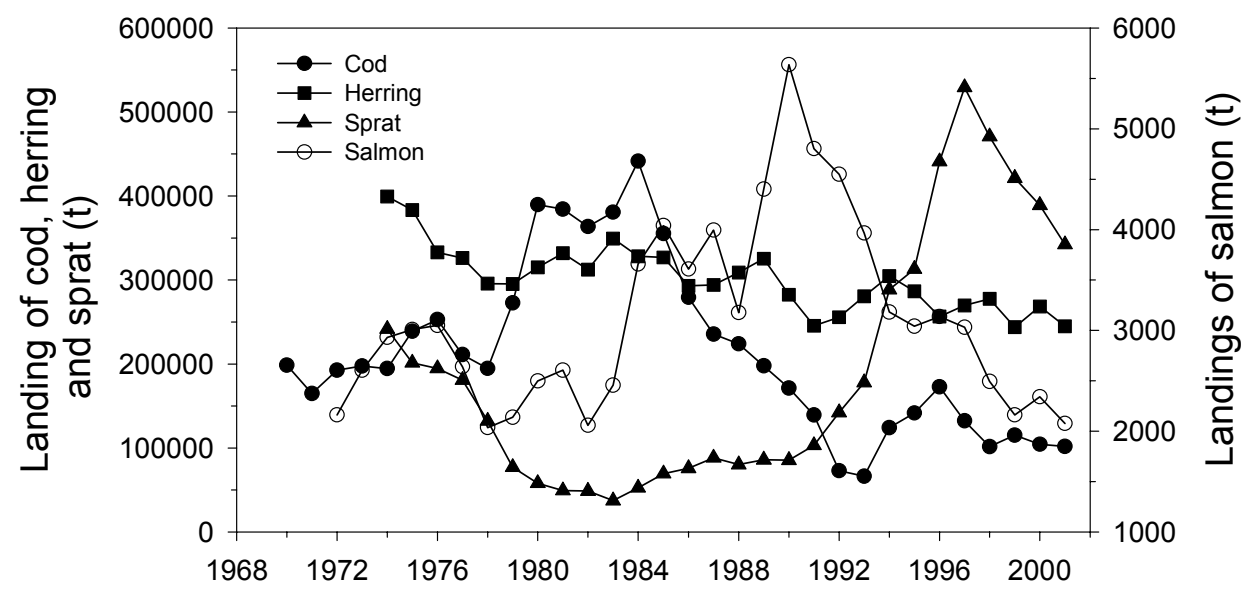

Figure S1. Commercial landings of cod (ICES Subdivisions 22-32; Fig. 1), herring (ICES Subdivisions 25-32 including the Gulfs of Riga, Finland, and Bothnia, and the Bothnian Sea), sprat (ICES Subdivisions 22-32) and salmon (ICES Subdivisions 22-32). The landings data $(1,2)$ were dissaggregated spatially by subdivision for some analyses. 


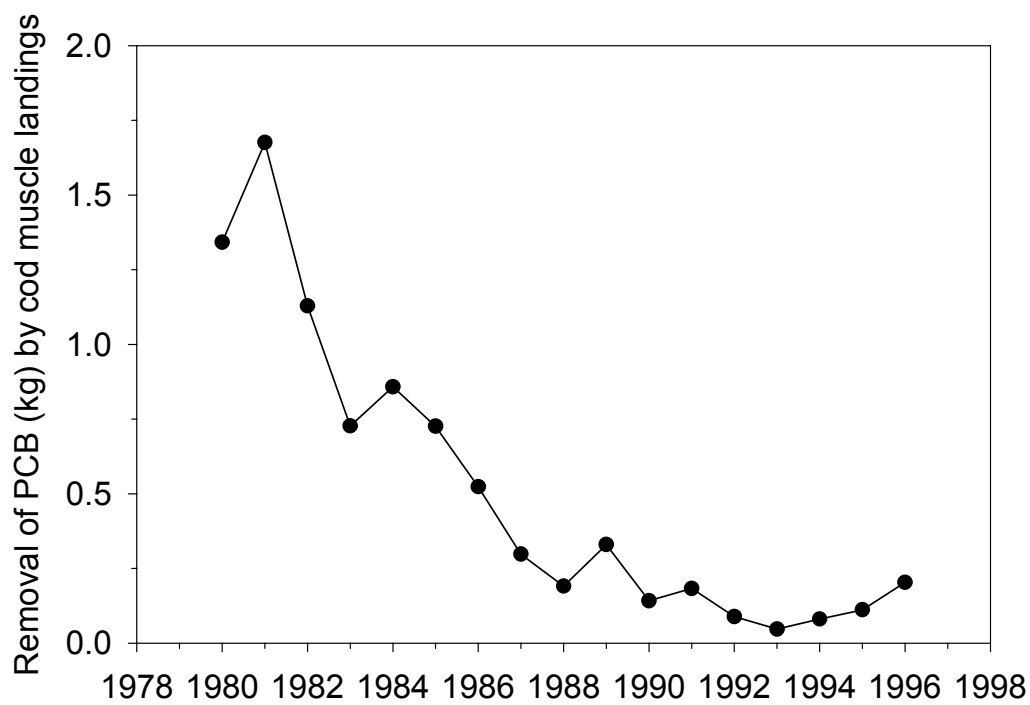

Figure S2. Time series of PCB removal from the Baltic Sea associated with the muscles of cod captured by the international cod fishery in ICES Subdivisions 25-32. Estimates are based on PCB concentrations measured by (3) and official landings statistics (1).

Estimation of PCB removal associated with cod muscle:

We estimated the removal of PCB associated with the landings of cod by the entire international commercial fishery in the Baltic Sea (ICES Subdivisions 22-32). This calculation was based on the PCB content in cod muscle. However there are relatively few published measurements of PCB concentrations in muscle of Baltic cod, and there are no time series available that are based on standard sampling and processing methods (4). 
We therefore considered whether correlations exist between muscle and liver PCB concentrations in cod, which in turn could be used to develop a time series of muscle-based PCB concentrations. (5) has shown that muscle and liver PCB concentrations in Baltic cod are equivalent when expressed on the basis of the phospholipid-free fraction of extractable lipids, and that liver PCB concentrations are higher than muscle PCB concentrations when expressed on total extractable lipid basis. The difference is due to the ability of different types of lipids to dissolve or store PCBs (5). The lipid basis for most of the extractions used in our data analyses is however based on total extractable lipids. Our calculation (below) of PCB removal with cod muscle, which assume that muscle and liver PCB concentrations are equal when expressed on a total lipid basis, will therefore overestimate the potential removal rate of PCB for this fishery component.

The calculation assumes that the proportion of cod muscle is similar to the skinless fillet yield of cod, which, according to (6), is $36 \%$. This value corresponds closely to an estimate of $40 \%$ for the proportion of cod body weight attributed to muscle (7). The lipid content of Baltic cod muscle is very low but varies seasonally (7). Since cod are captured throughout the year in the Baltic, we used the annual average cod muscle lipid content $(0.16 \%)$ measured by (7).

The time series of removal rates is shown in Figure S2. Compared with removals associated with cod liver and the herring or sprat fisheries (Fig. 3 of manuscript), this component of removal is very low. We note however that $\mathrm{PCB}$ concentrations in cod muscle lipid were much higher in the late 1970s than in the time period covered by this analysis and removal rates may have been higher than those shown in this time series. 


\section{References}

(1) ICES. ICES CM 2002/ACM: 172002.

(2) ICES. ICES CM 2002/ACFM: 132002.

(3) Bignert, A.; Olsson, M.; Persson, W.; Jensen, S.; Zakrisson, S.; Litzén, K.; Eriksson, U.; Häggberg, L.; Alsberg, T. Env. Poll. 1998, 99, 177-198.

(4) Falandysz, J. Z. Lebensm Unters Forsch 1986, 182, 136-139.

(5) Schneider, R. Meeresforsch. 1982, 29, 69-79.

(6) FAO. Yield and nutritional value of the commercially more important fish species. Torry Research Station, Aberdeen Scotland. 309, 1-187. (1989). Rome, Food and Agriculture Organization of the United Nations. FAO Fisheries Technical Paper.

(7) Bogucki, M.; Trzesinski, P. J. de Conseil 1950, 16, 208-210. 